\title{
THE REPEATED PRETEST-POSTTEST SINGLE-SUBJECT EXPERIMENT: A NEW DESIGN FOR EMPIRICAL CLINICAL PRACTICE*
}

\author{
BRUCE A. THYER and GEORGE C. CURTIS \\ The University of Michigan
}

\begin{abstract}
Summary-The logic of a new design for empirical clinical practice, the repeated pretest-posttest experiment, is described. This design is readily applicable by individual practitioners in the human services, possesses high internal validity, and presents minimal intrusiveness into the delivery of service. A single-case study is used to illustrate the application of the repeated pretest-posttest experiment in clinical research.
\end{abstract}

Single-case experimental designs have gained increasing acceptance as a valuable tool for research and development in the human services. Numerous sources describe the application of such designs in the fields of psychiatry (Liberman et al., 1973), psychology (Hersen and Barlow, 1976), social work (Jayaratne and Levy 1979), education (Blackman and Silberman, 1975), and nursing (LeBow, 1975). Unfortunately, despite the widespread dissemination of single-case experimental methodology, the designs are not widely employed at the level of the individual practitioner in these disciplines. A number of reasons have been advocated to explain this phenomenon but what is perhaps the most significant drawback to the clinical employment of single-subject research strategies is the fact that those designs which are most readily applied by the individual practitioner typicall: possess rather low levels of internal validity (Thomas, 1978). Those designs with the potential for high internal validity often present too many constraints on the delivery of effective service (i.e. extended or multiple baselines, reversal or withdrawal phases). What is needed to facilitate the application of single-subject research methodology is the development of experimental designs of high internal validity which are easily applicable in the service setting. A number of steps have been taken in this direction. See, for example, the designs described by Watson and Workman (1981), and by Barlow and Hayes (1979). The present study describes the experimental logic and application of another such design, the repeated pretest-posttest single case experiment.

\section{DESCRIPTION AND EXPERIMENTAL LOGIC OF THE DESIGN}

The traditional AB design employs repeated measures of the subject's behavior over two time periods, a baseline phase and during intervention. If visually significant changes are detected, a treatment effect may be inferred. Other factors which may give rise to changes in the client which are not excluded by this design include, among others, the threats of concurrent history, maturation, testing, physical changes, regression and drug use. Even with the best of data obtained from $A B$ designs the practitioner rarely has

*Portions of this paper were presented at the annual meeting of the Association for Behavior Analysis, Milwaukee, Wisconsin, May 27-31 1982.

Address all correspondence to Bruce A. Thyer, Ph.D., Anxiety Disorders Program, Adult Psychiatric Hospital, The University of Michigan, Ann Arbor, MI 48109, U.S.A. 
unambiguous documentation of the effects of treatment.

With interventions where a treatment effect may be expected immediately following a therapy session, such as procedures employing modeling, desensitization, skill acquisition or refinement, and reinforcement of successive approximations, an alternative strategy to the $\mathrm{AB}$ design suggests itself. In the repeated pretest-posttest design, measures are taken of the client's behavior immediately before and after each treatment session. Since only a small amount of time passes between the measures taken at each session a number of threats to internal validity are excluded. Maintenance of the changes induced in one treatment session are assessed by measuring the behavior at the beginning of the next session. Visual inspection of the data, both pre and post each treatment session and across sessions, permits a robust behavior analysis of the effects of intervention. If multiple response system assessment methodology is employed (i.e. concurrent measurement of behavioral, subjective and physiological aspects of the problem), internal validity is further strengthened (Ciminero, 1977). Since the practitioner collects the data, certain problems associated with selfmonitoring by the client in the natural environment, such as missing or erroneous information, are lessened. The following experimental case study illustrates the use of the repeated pretestposttest design.

\section{CASE ILLUSTRATION}

\section{Client}

The client was a 26-yr-old housewife who was seen at the Anxiety Disorders Program for complaints of a severe fear of frogs. The onset of her fear seemed to stem from a traumatic incident 18 months earlier when she was mowing thick grass in the yard of her home on a riverbank. She apparently ran over a group of frogs, as she was suddenly surrounded by a number of the hopping animals and at the same time several were chopped up by her lawn mower. Bloody pieces of frog spewed from the machine. She became so upset that she had to stop mowing the grass and go inside her home. She had not been able to mow the yard from that episode until her self-referral to the clinic. Her life became a misery. In the evenings she could hear croaking frogs at the riverbank along the back yard. On several occasions frogs found their way into her home, forcing her to leave the house until they had been removed by a neighbor or her spouse. She had occasional upsetting dreams about frogs which led to insomnia. She was happily married and was in her third trimester of pregnancy when interviewed. She fulfilled DSM III criteria for simple phobia.

\section{Treatment}

Treatment options were presented to the client, who elected to pursue real life exposure therapy, wherein she would gradually increase her contact with live frogs under controlled, therapist guided conditions. Detailed descriptions of the technique can be found in earlier publications (Thyer, 1981, 1983; Curtis et al., 1976). Her obstetrician was contacted and he gave his consent to the use of the selected approach.

\section{Assessment}

Behavioral approach tests (BAT) were used to quantify her anxiety about frogs (Levis, 1969). The patient was seated at one end of the consulting room, told that a live frog was in the next room, and asked to rate her anxiety level using the subjective units of distress (SUD) scale (Wolpe, 1973). This scale, previously taught to the patient, asks for a self-report rating of anxiety, with zero representing a state of complete calm and relaxation, and 100 complete panic, or as frightened as she had ever been. With the patient's consent, the clinician entered the room with a cart bearing an open aquarium containing a live frog and stopped at a distance of 15 feet away. Ratings were obtained at this distance for SUDs and pulse. Heartrate was recorded from a Gulf and Western Cardiotach (model 4600A) with a visual display. The photoplythesmograph was attached to the index finger of the patient's left hand. Permission was 
then asked to come within 12 feet, ratings recorded, then 10 feet and so forth. Data was recorded on a standardized BAT form, with increments of proximity ranging from having the frog out of the room (OR), 15 feet to one foot away, touching the aquarium containing the frog or indirect touch (IT), directly touching the frog (DT), holding a frog (HOLD) and allowing the frog to have essentially unlimited contact with her person (UC). The BAT was given immediately before and after each exposure therapy session.

Phobic anxiety was thus operationally defined via a self-report measure (SUDs rating at various increments of proximity), a behavioral measure (closest approach the client would allow during the test) and a physiological measure of autonomic arousal (heartrate at the various increments of proximity), and at least minimally conformed to the requirements for complete multiple response system assessment.

\section{RESULTS}

A typical treatment session lasted from between $1 \frac{1 / 2}{2}$ and $2 \mathrm{hr}$ of continuous exposure and a total of six sessions were required before the patient was free of phobic avoidance and subjective anxiety. Slight tachycardia was still apparent but she was otherwise symptom free. Concurrent with the improvements obtained within the clinic environment, the patient regained the ability to walk freely about her property, and her frog-related nightmares and subsequent insomnia disappeared, permitting normal sleep. Data for the six treatments is presented in Figs. 1-6. In these graphs, the ordinate represents measures of heartrate and subjective anxiety, while each of the standardized increments of proximity are indicated on the abscissa. Hence, the rightmost data points for SUDs and pulse correspond with the closest level of approach obtained during the test. Each graph displays the data taken before and after each treatment session.

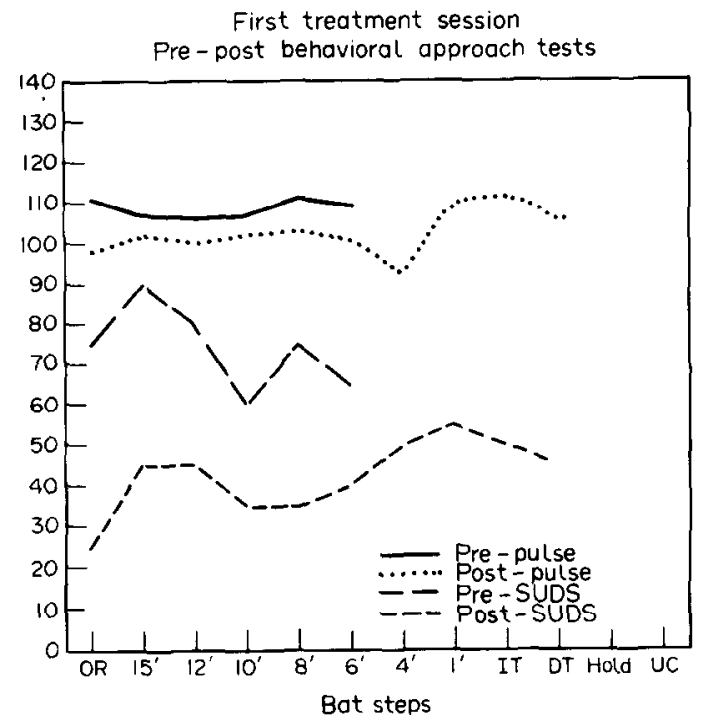

Fig. 1.

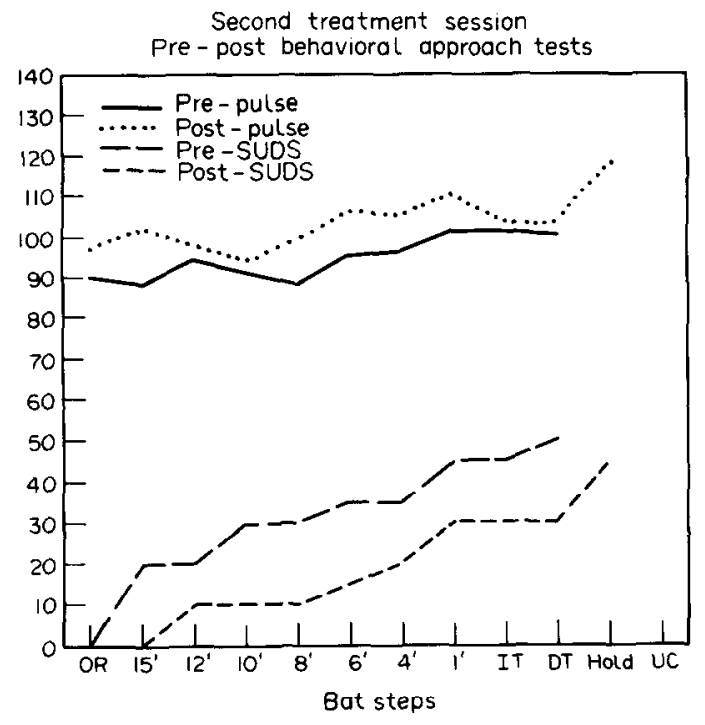

Fig. 2.

As can be seen, marked improvements were observed following each exposure therapy session, improvements which were largely retained at the pre-treatment assessment conducted the following week. Telephone contact with the patient 5 months later revealed satisfactory maintenance of improvements and the absence of any functional limitations. 


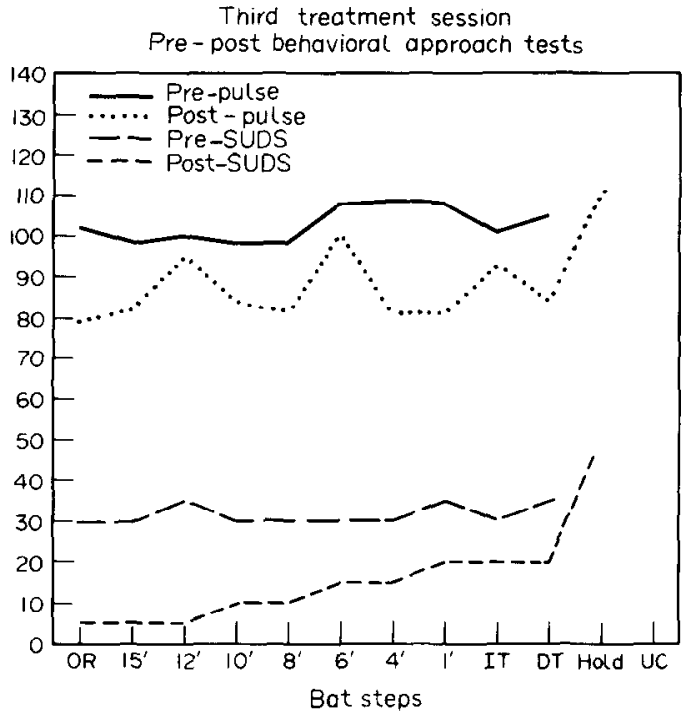

Fig. 3.

Fourth treatment session Pre-post behavioral approach tests

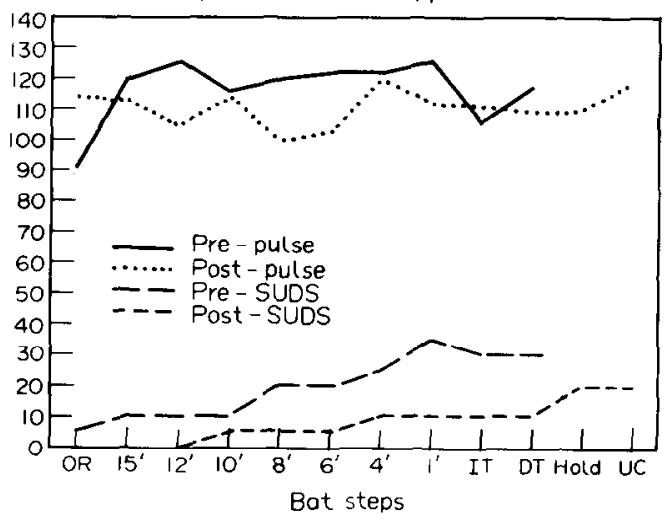

Fig. 4.

\section{DISCUSSION}

The internal validity of the repeated pretestposttest single-subject experiment may be plausibly argued to be quite high. The short time period occurring between the pre- and posttreatment session behavioral approach tests reduces the possibility that factors apart from exposure therapy induced the observed improvements, factors such as concurrent history, maturation, drugs, health changes, regressions, etc. The
Fifth treatment session

Pre-post behavioral approoch tests

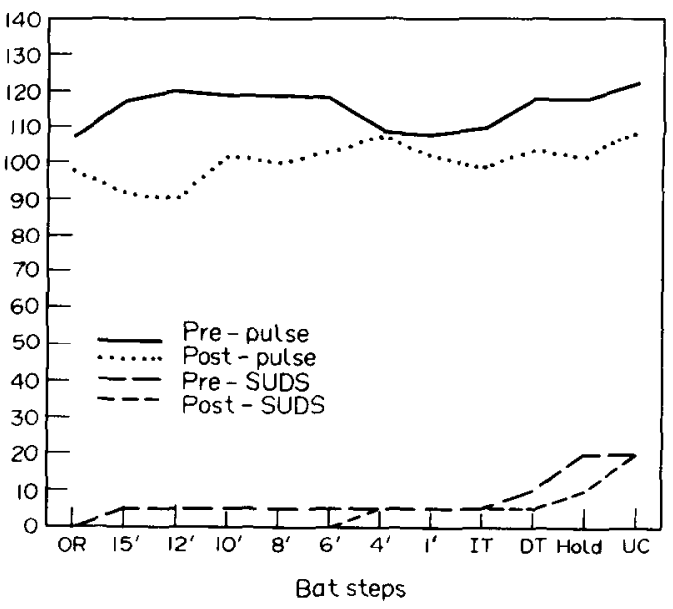

Fig. 5 .

Sixth treatment session

Pre-post behavioral approach tests

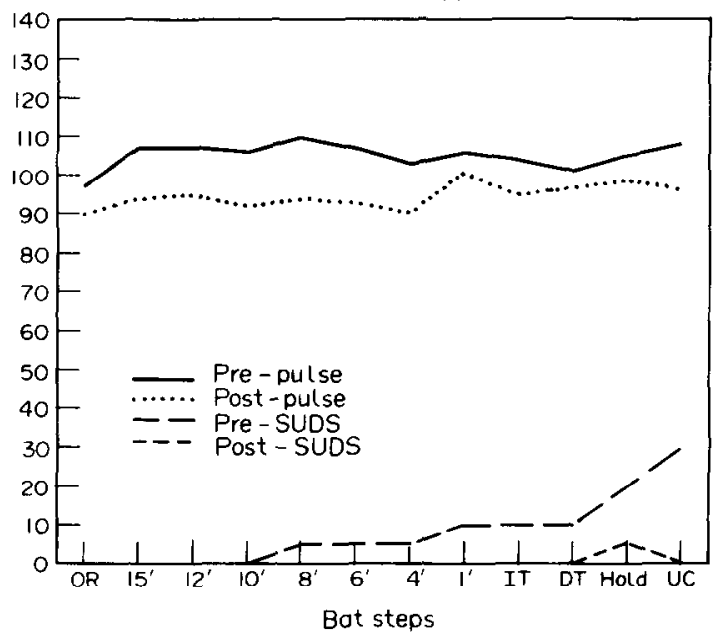

Fig. 6.

maintenance of observed improvements from one treatment session is assessed via the pretreatment BAT given at the beginning of the following session a week later. The design made minimal demands upon either client or therapist in terms of time, delay of treatment, data acquisition or resources, yet provides a reasonably robust assessment of the effects of treatment. An additional advantage of this approach is that it can guide the therapist in making 
treatment decisions. Should the data indicate no improvement or that the client was becoming sensitized to frogs, as opposed to desensitized, alternatives would have been indicated regarding the conduct of therapy.

For those interventions for which it is applicable, procedures with fairly immediate treatment effects, the repeated pretest-posttest single-subject experiment fulfills the requisites of applied behavior analysis (Baer, Wolf and Risley, 1968). It is readily applicable by practitioners in the human services and is less intrusive than other internally valid single-case designs. Data collection with this client typically involved about 5 min of each session. Furthermore, the focus of treatment was socially relevant and of importance to the client, i.e. restrictions on her daily activities and curtailment of her enjoyment of life. It is behavioral in that it provides a practical answer to the question of how to get an individual to do something effectively, employing dependent and independent variables that are readily quantifiable. It is analytic in that it permits a clear determination of the functional relationship between treatment and outcome, i.e. control over the problem is attained.

As with all clinical research experiments, the strength of the repeated pretest-posttest singlesubject design is limited by the validity of the dependent variables employed by the therapist, and by the clarity of the data obtained. Choosing measures highly reactive to the effects of repeated testing, or therapeutic interventions which are delayed or sporadic in their effects, will weaken the practitioner's ability to make causal inferences. Every single-subject research design presents to the clinician certain strengths, weaknesses and compromises to be made. The purpose of this brief report has been to expand upon the choices available for the researcher in human service settings who wishes to engage in empirical clinical practice.

\section{REFERENCES}

Baer D., Wolf M. and Risley T. (1968) Some current dimensions of applied behavior analysis, J. Appl. Behav. Anal. 1, 91-97.

Barlow D. and Hayes S. (1979) Alternating treatments design: One strategy for comparing the effects of two treatments in a single subject, J. Appl. Behav. Anal. 12, 199-210.

Blackham G. and Silberman A. (1975) Modification of Child and Adolescent Behaviour (second edition), Wadsworth, Belmont CA.

Ciminero A. (1977) Behavioral assessment: An overview. In Handbook of Behavioral Assessment (Ed. by Ciminero A., Calhoun K. and Adams H.), pp. 3-13. Wiley, New York.

Curtis G., Nesse R., Buxton M., Wright J. and Lippman D. (1976) Flooding in vivo as a research tool and treatment method for phobias, Comprehen. Psychiat. 17, 153-160.

Hersen M. and Barlow D. (1976) Single Case Experimental Designs, Pergamon, New York.

Jayaratne S. and Levy R. (1979) Empirical Clinical Practice. Columbia University Press, New York.

LeBow M. (1975) Applications of behavior modification in nursing practice, In Progress in Behavior Modification (Ed. by Hersen M., Eisler R. and Miller P.), Vol. 2, pp. 137-177. Academic Press, New York.

Levis D. (1969) The phobic test apparatus: An objective measure of human avoidance behavior to small objects, Behav. Res. Ther. 7, 309-315.

Liberman R., Davis J., Moon W. and Moore J. (1973) Research design for analyzing drug-environment-behavior interactions, J. Nerv. Ment. Dis. 150, 432-439.

Thomas E. (1978) Research and service in single-case experimentation: Conflicts and choices, Social Work Res. Abs. 14 (4), 20-31.

Thyer B. (1981) Prolonged in vivo exposure therapy with a 70-yr-old woman, J. Behav. Ther. \& Exp. Psychiat. 12, 69-71.

Thyer B. (1983) Treating anxiety disorders with exposure therapy, Social Casework 64, 77-82.

Watson P. and Workman E. (1981) The non-concurrent multiple baseline across-individuals: An extension of the traditional multiple baseline design, J. Behav. Ther. \& Exp. Psychiat. 12, 257-259.

Wolpe J. (1973) The Practice of Behavior Therapy. Pergamon, New York. 